\title{
Influences of ethanol and temperature on sucrose-evoked response of gustatory neurons in the hamster solitary nucleus
}

\author{
Cheng-Shu Li', Ki-Myung Chung ${ }^{2}$, Kyung-Nyun $\mathrm{Kim}^{2}$, and Young-Kyung Cho ${ }^{2, *}$ \\ 'Department of Anatomy, School of Medicine, Southern Illinois University, Carbondale, IL 62901, USA, ${ }^{2}$ Department of Physiology and Neuroscience, College of \\ Dentistry and Research Institute of Oral Science, Gangneung-Wonju National University, Gangneung 25457, Korea
}

\section{ARTICLE INFO}

Received August 3, 2021

Revised September 3, 2021

Accepted September 13, 2021

${ }^{*}$ Correspondence

Young-Kyung Cho

E-mail:ykcho@gwnu.ac.kr

\section{Key Words}

Electrophysiology

Ethanol

In vivo

Solitary nucleus

Sucrose
ABSTRACT Taste-responsive neurons in the nucleus of the solitary tract (NST), the first gustatory nucleus, often respond to thermal or mechanical stimulation. Alcohol, not a typical taste modality, is a rewarding stimulus. In this study, we aimed to investigate the effects of ethanol (EtOH) and/or temperature as stimuli to the tongue on the activity of taste-responsive neurons in hamster NST. In the first set of experiments, we recorded the activity of 113 gustatory NST neurons in urethane-anesthetized hamsters and evaluated responses to four basic taste stimuli, $25 \% \mathrm{EtOH}$, and $40^{\circ} \mathrm{C}$ and $4^{\circ} \mathrm{C}$ distilled water $\left(\mathrm{dH}_{2} \mathrm{O}\right)$. Sixty cells responded to $25 \% \mathrm{EtOH}$, with most of them also being sucrose sensitive. The response to $25 \% \mathrm{EtOH}$ was significantly correlated with the sucrose-evoked response. A significant correlation was also observed between sucrose- and $40^{\circ} \mathrm{C} \mathrm{dH}_{2} \mathrm{O}$ - and between $25 \% \mathrm{EtOH}$ - and $40^{\circ} \mathrm{C} \mathrm{dH}_{2} \mathrm{O}$-evoked firings. In a subset of the cells, we evaluated neuronal activities in response to a series of EtOH concentrations, alone and in combination with $32 \mathrm{mM}$ sucrose (EtOH/Suc) at room temperature $\left(\mathrm{RT}, 22^{\circ} \mathrm{C}-23^{\circ} \mathrm{C}\right), 40^{\circ} \mathrm{C}$, and $4^{\circ} \mathrm{C}$. Neuronal responses to EtOH at $\mathrm{RT}$ and $40^{\circ} \mathrm{C}$ increased as the concentrations increased. The firing rates to $\mathrm{EtOH} / \mathrm{Suc}$ were greater than those to $\mathrm{EtOH}$ or sucrose alone. The responses were enhanced when solutions were applied at $40^{\circ} \mathrm{C}$ but diminished at $4^{\circ} \mathrm{C}$. In summary, EtOH activates most sucrose-responsive NST gustatory cells, and the concomitant presence of sucrose or warm temperatures enhance this response. Our findings may contribute to elucidate the neural mechanisms underlying appetitive alcohol consumption.

\section{INTRODUCTION}

We naturally prefer palatable food and avoid unsavory food or toxic substance $[1,2]$. From an evolutionary point of view, these preferences represent a basic mechanism of survival, guiding us toward important sources of energy and protecting us from potentially harmful substances. Occasionally taste and texture of some foods are affected by temperature [3]. Same foods can induce more appetite and/or flavor experience when we are hungry [4]. We also often consume more food than we would need to maintain nutritional homeostasis $[5,6]$. It is now clear that motivation to eat as well as taste perception are affected by various physiological and psychological factors $[5,6]$. Unravelling such modulatory factors and the mechanisms behind their influence is critical to help us to understand dysregulation of eating behavior during disease.

Such modulation of ingestive behavior or gustation on neuronal activity is also observed in the central taste pathways. Sweet stimulus-evoked neuronal firings of taste neurons in the nucleus of the solitary tract (NST), which is the first taste nucleus in the pathway, is modulated by a number of physiological conditions, such as blood glucose, insulin, or glucagon levels [7-10]. Conditioned taste aversion or preference also modulates firing activity of NST gustatory neurons $[11,12]$. Altogether, these studies sug-

\section{(i) (8)}

This is an Open Access article distributed under the terms of the Creative Commons Attribution Non-Commercial License, which permits unrestricted non-commercial use, distribution, and reproduction in any medium, provided the original work is properly cited. Copyright $\odot$ Korean J Physiol Pharmacol, pISSN 1226-4512, elSSN 2093-3827
Author contributions: C.S.L. and Y.K.C. designed the experiments and performed extracelluar recordings. K.M.C. and K.N.K. analyzed the data and prepared the figures. Y.K.C. wrote the manuscript with inputs from all authors. 
gest that gustatory neurons in the NST respond to information related to nutritional and taste-related learning.

Alcohol is one of most consumed beverage world-wide, although it is not classified as a basic taste element [13]. Alcohol, especially ethanol (EtOH), is frequently abused and represent a world-wide public health concern. Understanding the neural mechanisms underlying appetitive alcohol intake has been a research priority. The oral intake of alcohol is accompanied by perception of flavor which, by definition, is composed of taste, olfaction, and chemosensory irritation [14]. Human and animals detect sweet and bitter taste in alcohol $[15,16]$. Importantly, one study has demonstrated a close association between alcohol intake and preference for sweets in both humans and animals [17]. Electrophysiological studies have started to explore the relationship between alcohol and sweet taste at the level of the gustatory nerve and neurons. Hellekant et al. [18] reported that alcohol activated chorda tympani (CT) branch of the facial nerve, which innervate taste buds in the anterior tongue. Single-fiber recording revealed responses to alcohol in sucrose-best fibers in rats [19]. A positive correlation between the neuronal response to alcohol and sucrose was demonstrated in the NST neurons in the rat $[20,21]$. In vivo recording of taste neurons in the hamster parabrachial nuclei $(\mathrm{PbN})$ also showed a positive correlation between sucrose- and EtOH-evoked responses [22]. Interestingly, heating and cooling of the tongue induces taste sensation. Warming the tongue produces sweet sensation [23]. In particular, the perception of sweetness was positively correlated with temperature of the solution $[24,25]$. Whether alcohol response is dependent on temperature is not known so far. For this reason, in this study we sought to examine whether the oral application of EtOH activates gustatory neurons in the NST in the hamster, and whether this EtOH-induced activity correlated with those evoked in response to sucrose and temperature of the solution applied.

\section{METHODS}

\section{Animal care and surgery}

The experimental procedures were reviewed and approved by the Institutional Animal care and Use Committee of Southern Illinois University at Carbondale (IACUC approval No. 04-041). Young adult male Syrian golden hamsters (Mesocricetusauratus, $n=46$ ), weighing between $128 \mathrm{~g}$ and $174 \mathrm{~g}$, were deeply anesthetized with Urethane (1.7 g/kg i.p.). Each animal was tracheotomized and mounted in a stereotaxic instrument (SR-6N; Narishige, Tokyo, Japan) using a non-traumatic head holder. The surgical procedures to expose the brainstem for in vivo recording were described in detaril in previous studies [26-28].

\section{Single unit recording in the NST and best-stimulus classification}

Single-barrel glass micropipettes (1-2 $\mu \mathrm{m}$ tip diameter, 5-7 $\mathrm{M} \Omega$ resistance) filled with $2 \%$ (wt/vol) solution of Chicago Blue dye (Sigma, St. Louis, MO, USA) in $0.5 \mathrm{M}$ sodium acetate were used for extracellular recording of single-unit action potentials in the rostral portion of the NST. Extracellular action potentials were amplified (NeuroLog; Digitimer Ltd., Hertfordshire, UK), discriminated with a dual time-amplitude window discriminator (Bak DDIS-1; Bak Electronics, Germantown, MD, USA). CED 1401 interface board and Spike2 software (Cambridge Electronic Design, Cambridge, UK) were used for taste stimulus delivery, data acquisition and analysis. The gustatory NST neurons were initially identified by response to electrical stimulation $(\leq 40$ $\mu \mathrm{A}, 500 \mathrm{~ms}$ duration at $1 / 3 \mathrm{~Hz}$ ) to the anterior tongue. Taste stimuli presented to the anterior tongue were: $0.032 \mathrm{M}$ sucrose, sodium chloride $(\mathrm{NaCl})$, quinine hydrochloride $(\mathrm{QHCl})$, and $0.0032 \mathrm{M}$ citric acid. These concentrations evoke approximately equal multiunit taste responses in the hamster NST [29]. The taste solution was delivered by a gravity-flow system composed of a computer controlled two-way solenoid-operated valve connected to a distilled-water rinse reservoir and a stimulus funnel. The stimulation sequence, was a continuous flow initiated by the delivery of distilled water $\left(\mathrm{dH}_{2} \mathrm{O}\right)$ for $10 \mathrm{sec}$, followed by $10 \mathrm{sec}$ of a taste solution, and by $10 \mathrm{sec}$ of $\mathrm{dH}_{2} \mathrm{O}$ rinse. The flow rate was 2 $\mathrm{ml} / \mathrm{s}$. The tongue was rinsed with $\mathrm{dH}_{2} \mathrm{O}(>50 \mathrm{ml})$ between solution stimulations. Each cell was categorized as one of four beststimulus neuron based on response to four taste stimuli. If a cell fired greatest to sucrose stimulation, this neuron was classified as sucrose-best $(\mathrm{Sb})$ cell. Similarly, each gustatory neuron was classified as $\mathrm{NaCl}$-best $(\mathrm{Nb})$, citric acid-best $(\mathrm{Cb})$ or $\mathrm{QHCl}$-best $(\mathrm{Qb})$ cell.

\section{Taste/ethanol/thermal stimulation of the tongue}

Each neuron was first tested with four room temperature (RT: $22^{\circ} \mathrm{C}-23^{\circ} \mathrm{C}$ )-taste solutions. To investigate whether taste-responsive neurons in the NST also respond to EtOH/thermal stimulation, $25 \% \mathrm{EtOH}$ or thermal stimuli were presented to the anterior tongue, after taste trials. The concentration of $25 \% \mathrm{EtOH}$, compared with other concentrations, had showed the maximum effect in producing neuronal firings from NST taste neurons in the pilot study. Thermal stimulations were accomplished by presenting $4^{\circ} \mathrm{C}$ and $40^{\circ} \mathrm{C} \mathrm{dH}_{2} \mathrm{O}$ to the anterior tongue. The EtOH solutions used in the experiments were made by diluting from $100 \%$ ethanol (Sigma). In addition to the best-stimulus category, each taste-responsive NST cell was classified into EtOH-responsive or EtOH-non-responsive group.

To ensure accurate cooling and warming temperature of thermal stimulation, the stimulus delivery system was rinsed with the same degree $\left({ }^{\circ} \mathrm{C}\right)$ stimulus solution without the solution actually 
contacting the tongue, immediately prior to stimulus delivery. The temperature was monitored with a digital remote probe thermometer (YX-90205; Davis Instruments, Hayward, CA, USA) placed at the exit of the stimulus delivery system.

In a subset of EtOH-responsive taste neurons, EtOH-dose dependency was investigated. Cells were tested with RT-EtOH solution of $3,5,10,15,25$, and $40 \%$ in random order, followed by $4^{\circ} \mathrm{C}$ and $40^{\circ} \mathrm{C} \mathrm{dH_{2 }} \mathrm{O}$. The neuronal firings in response to a mixture of $32 \mathrm{mM}$ sucrose and 25\% $\mathrm{EtOH}$ (EtOH/Suc) were recorded in some cells. For a small number of cells, the effect of temperature of solutions was also studied. Sucrose- and/or EtOH-evoked neuronal firings were compared at room temperature, $4^{\circ} \mathrm{C}$ or $40^{\circ} \mathrm{C}$.

\section{Histology}

At the end of each experiment, the last recording site was marked by passing a $10 \mu \mathrm{A}$ cathodal current through the recording electrode for $10 \mathrm{~min}$ (5 sec ON-OFF) to deposit a spot of Chicago Sky Blue dye. The hamster was perfused through the heart with $4 \%$ formalin. Brains were removed, frozen, and cut coronally in $40-\mu \mathrm{m}$ sections. Sections were stained with Neutral Red. These markings were located in the rostral NST which coincided with the area of recording sites in the previous studies [26-28].

\section{Data analysis}

Taste-evoked neuronal response was calculated as the mean number of action potentials (impulses/s) during the first $5 \mathrm{sec}$ of chemical stimulation minus the mean number of spikes during 5 $\mathrm{sec}$ of distilled water before the taste delivery, which was defined as baseline activity. A taste and $\mathrm{EtOH}$ responses were regarded as effective if it was $\geq 2$ standard deviation above the baseline activity. The entropy $(\mathrm{H})$ of each neuron, which is a measure of its breadth of responsiveness, was calculated using excitatory components of responses to four standard taste stimuli by the formula contrived by Drs. Smith and Travers [30].

Analysis of variance (ANOVA) was used to compare differences in mean firing rates to taste stimulus or $\mathrm{EtOH}$ and in entropies between $\mathrm{EtOH}$-responsive and $\mathrm{EtOH}$-non-responsive neurons across among taste stimuli. Comparisons of individual gustatory responses between $\mathrm{EtOH}$-responsive and $\mathrm{EtOH}$-non-responsive groups were assessed using Student t-tests. Pearson's correlation coefficient was used to assess the linear relationships between pairs of sucrose-, EtOH- or $40^{\circ} \mathrm{C} \mathrm{dH}_{2} \mathrm{O}$-evoked responses. Comparison of the number of neurons in each category was made using the chi-square test. All means were reported with SE (standard error) unless remarked otherwise. Statistical analyses were performed using IBM SPSS statistics version 25 (IBM Co., Armonk, NY, USA).

\section{RESULTS}

We extracellularly recorded from a total of 113 taste-responsive NST neurons and examined its responsiveness to $25 \% \mathrm{EtOH}$ and to four basic taste stimuli. Activity was monitored in the rostral regions of the NST, where the dorsal cochlear nucleus is appeared. This region is often used to record taste-responsive neurons $[27,28,31]$. The vast majority of gustatory cells in this area project to the next taste relay, the $\mathrm{PbN}$ in hamsters [26].

\section{Gustatory vs. EtOH-responsiveness}

Some taste neurons fired in response to all four taste stimuli at RT. Other neurons responded to one, two, or three taste stimuli only. Each neuron was categorized into one of four groups based on the stimulus that produced maximum neuronal responses. From 113 recorded cells, we found $36 \mathrm{Sb}, 34 \mathrm{Nb}, 18 \mathrm{Cb}$, and 25 $\mathrm{Qb}$ cells. Sb cells were the most frequently recorded; although the numbers of each best-stimulus cells were not equal, the distribution among the four best-stimulus groups was not significantly different $\left(\chi^{2}=7.389, \mathrm{df}=3, \mathrm{p}=0.060\right)$. All recorded taste-responsive cells were also subdivided in two groups: $\mathrm{EtOH}$-responsive $(\mathrm{n}=60)$ if they fired significantly in response to $25 \% \mathrm{EtOH}$; and EtOH-non-responsive group $(n=53)$ otherwise. More than a half of taste-responsive neurons responded significantly to $25 \% \mathrm{EtOH}$ $(60 / 113,53.1 \%)$. Sb cells constituted the cells that responded to $\mathrm{EtOH}$ the most (33/36, 91.7\%).

Entropies of EtOH-responsive neurons were greater than those of EtOH-non-responsive cells, despite best-stimulus category. EtOH-responsive and non-responsive neurons differed in entropy despite best-stimulus category $(\mathrm{F}[1,105]=19.569, \mathrm{p}<0.001$, oneway ANOVA). Significant differences between best-stimulus category groups could also be identified, despite responsiveness to $\mathrm{EtOH}(\mathrm{F}[3,105]=9.885, \mathrm{p}<0.001$, one-way ANOVA $)$. There was no significant interaction between EtOH-responsiveness and best-stimulus category on entropy $(\mathrm{F}[3,105]=2.238, \mathrm{p}=0.088$, one-way ANOVA). Data are summarized in Table 1.

Fig. 1 shows a summary of the neuronal firing properties of the

Table 1. Mean entropy of NST taste neurons as a function of EtOH-responsiveness and best stimulus

\begin{tabular}{lccccc}
\hline \multirow{2}{*}{ Variable } & \multicolumn{2}{c}{ EtOH-responsive } & & \multicolumn{2}{c}{ EtOH-non-responsive } \\
\cline { 2 - 3 } \cline { 5 - 6 } & $\begin{array}{c}\text { No. of } \\
\text { neurons }\end{array}$ & Value & & $\begin{array}{c}\text { No. of } \\
\text { neurons }\end{array}$ & Value \\
\hline $\mathrm{Sb}$ & 33 & $0.64 \pm 0.04$ & 3 & $0.12 \pm 0.08$ \\
$\mathrm{Nb}$ & 18 & $0.75 \pm 0.05$ & & 16 & $0.57 \pm 0.07$ \\
$\mathrm{Cb}$ & 3 & $0.86 \pm 0.04$ & & 15 & $0.74 \pm 0.04$ \\
$\mathrm{Qb}$ & 6 & $0.87 \pm 0.02$ & & 19 & $0.70 \pm 0.03$ \\
Total & 60 & $0.71 \pm 0.03$ & & 53 & $0.64 \pm 0.03$ \\
\hline
\end{tabular}

Values are presented as mean \pm SE. NST, nucleus of the solitary tract; $\mathrm{EtOH}$, ethanol; Sb, sucrose-best; $\mathrm{Nb}, \mathrm{NaCl}$-best; $\mathrm{Cb}$, citric acid-best; Qb, quinine hydrochloride-best. 


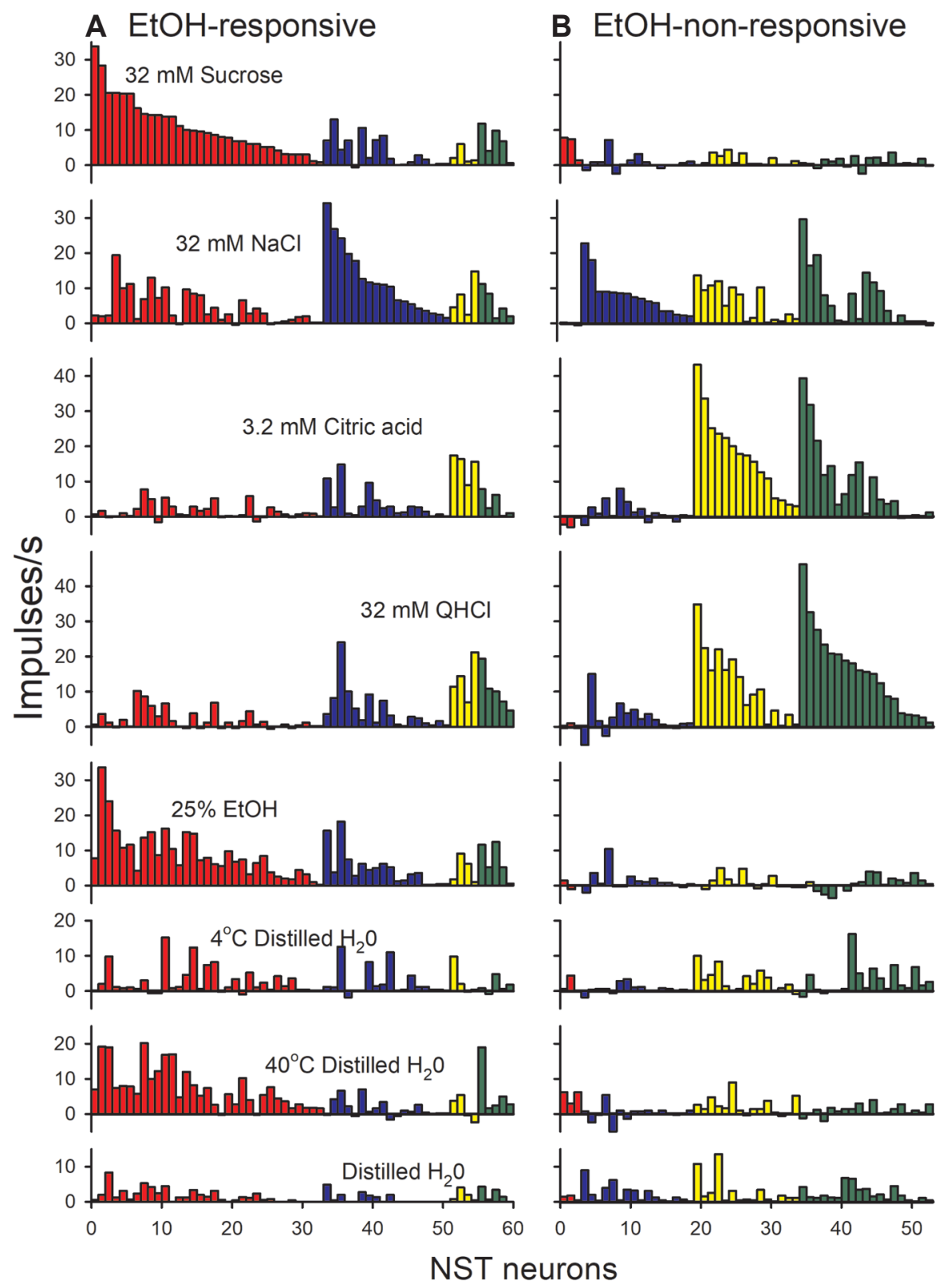

Fig. 1. Stimulus-evoked firings (impulses/s) of 113 nucleus of the solitary tract (NST) neurons, in response to four basic taste stimuli, $25 \%$ ethanol (EtOH), and distilled water $\left(\mathrm{dH}_{2} \mathrm{O}\right)$ at $40^{\circ} \mathrm{C}$ and $4^{\circ} \mathrm{C}$ in order from top to bottom panels. The last panel shows the mean number of spikes during $5 \mathrm{sec}$ of $\mathrm{dH}_{2} \mathrm{O}$ at a room temperature (baseline activity) before taste stimulus. Net taste responses, unaffected by somatosensory or thermal aspects of the test solutions, were calculated as a mean number of spikes during the first $5 \mathrm{sec}$ of each taste stimulus minus the baseline activity of same neuron. Each neuron was classified according to the taste stimulus that was the most effective in causing it to respond (best stimulus) and cells are arranged along the abscissa according to their best stimulus, with cells 1-33 being sucrose-best (Sb: red), 34-51 NaCl-best (Nb: blue), $52-54$ citric acid-best (Cb: yellow), and 55-60 QHCl-best (Qb: green) in EtOH-responsive groups (A). Similarly, 53 cells are arranged: 3 Sb, 16 Nb, 15 Cb, and 19 Qb are arranged in EtOH-non-responsive groups (B). Within each best-stimulus group, cells are arranged according to the magnitude of the response to their best stimulus. The response profile for any one cell in the figure can be read from top to bottom.

113 NST taste cells recorded. For each gustatory neuron, we present the responses to four taste stimuli, $25 \% \mathrm{EtOH}, 40^{\circ} \mathrm{C}$ and $4^{\circ} \mathrm{C}$ $\mathrm{dH}_{2} \mathrm{O}$. Cells are arranged in order of $\mathrm{Sb}, \mathrm{Nb}, \mathrm{Cb}$, and $\mathrm{Qb}$ in EtOHresponsive and non-responsive groups. The response pattern of all 113 cells to a single stimulus is read horizontally and that of a neuron to all 7 stimuli is seen vertically. Each bar represents the net response of a cell to a single stimulus. Fifty-two neurons out of the 60 EtOH-responsive cells (86.7\%) responded to sucrose stimulation. More than a half of EtOH-responsive cells were $\mathrm{Sb}$ neurons (33/60). In contrast, only eight neurons, including $3 \mathrm{Sb}$ cells, showed significant sucrose responses (15.1\%) in the EtOHnon-responsive group. EtOH-responsive and non-responsive 
neurons, despite best taste-stimuli group, did not differ in terms of neuronal firing $(\mathrm{F}[1,444]=1.988, \mathrm{p}=0.159)$. We also could not identify any differences between best-taste stimuli groups on neuronal firing, irrespective of EtOH-responsiveness $(\mathrm{F}[3,444]=$ $2.508, \mathrm{p}=0.058)$. However, we could find a significant interaction between both terms. $(\mathrm{F}[3,444]=17.467, \mathrm{p}<0.001)$. We also calculated the correlation between the responses to sucrose and to $25 \%$ $\mathrm{EtOH}$ for each cell. There was a significant correlation $(r=0.768$, $\mathrm{p}<0.001$ ) between both evoked responses across recorded cells.

The mean responses to the four taste stimuli, 25\% $\mathrm{EtOH}$, $40^{\circ} \mathrm{C}$ and $4^{\circ} \mathrm{C} \mathrm{dH}_{2} \mathrm{O}$ between EtOH-responsive and EtOH-nonresponsive cells are demonstrated in Fig. 2. Most Sb cells were

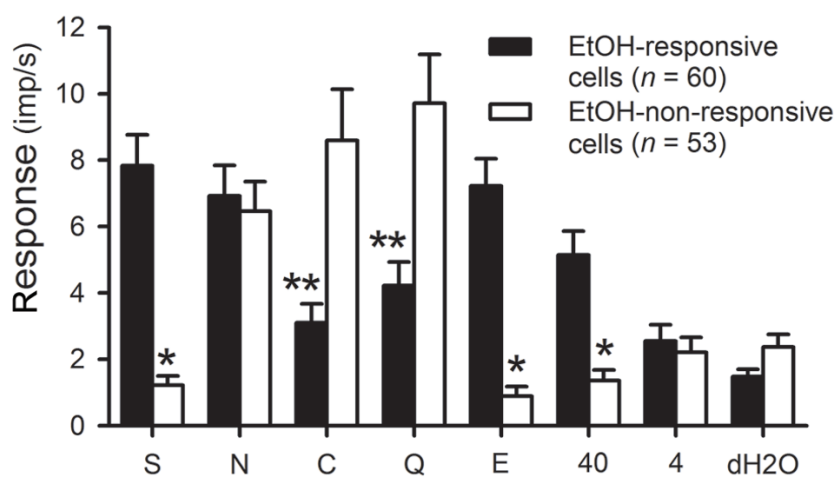

Fig. 2. Comparison of the mean firing rate $( \pm S E)$ of nucleus of the solitary tract (NST) neurons in response to four taste stimuli, $25 \%$ ethanol (EtOH), and distilled water $\left(\mathrm{dH}_{2} \mathrm{O}\right)$ at $40^{\circ} \mathrm{C}(40)$ and $4^{\circ} \mathrm{C}(4)$

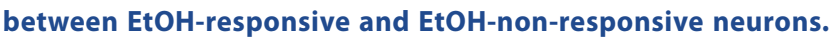
The last bars on the right of the figure indicate the baseline activities at room temperature. The solid bars indicate mean responses of $\mathrm{EtOH}-$ responsive neurons and open bars represent those of EtOH-non-

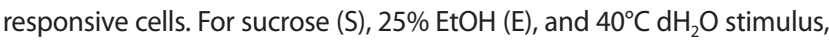
net responses in $\mathrm{EtOH}$-responsive neurons were significantly larger than those in $\mathrm{EtOH}$-non-responsive cells ( ${ }^{*} \mathrm{p}<0.001$, t-test). In comparison, citric acid (C)-, and $\mathrm{QHCl}(\mathrm{Q})$-evoked firings were significantly larger in $\mathrm{EtOH}$-non-responsive group ( ${ }^{* *} \mathrm{p}<0.005$, t-test). There were no differences across taste stimuli between $\mathrm{EtOH}$-responsive and $\mathrm{EtOH}-n$ nonresponsive cells for $\mathrm{NaCl}(\mathrm{N})$ and $4^{\circ} \mathrm{C} \mathrm{dH}_{2} \mathrm{O}$ stimuli. also EtOH-responsive. As seen in Fig. 1, sucrose-evoked responses were greater in EtOH-responsive group $(\mathrm{p}<0.001)$, whereas citric acid- and QHCl-induced firings were higher in the $\mathrm{EtOH}-$ non-responsive group $(\mathrm{p}<0.005)$. In addition to sucrose or $25 \%$ $\mathrm{EtOH}$, application of $40^{\circ} \mathrm{C}-\mathrm{dH}_{2} \mathrm{O}$ produced greater firing rates in the EtOH-responsive neurons when compared to EtOH-nonresponsive cells $(\mathrm{p}<0.001)$. We found a significant correlation between sucrose and $40^{\circ} \mathrm{C}$ responses $(r=0.726, \mathrm{p}<0.001)$, as well as between $40^{\circ} \mathrm{C}$ and $25 \%$ EtOH responses $(r=0.743, \mathrm{p}<0.001)$. In contrast, sucrose-evoked responses were not correlated with responses to $4^{\circ} \mathrm{C}_{2} \mathrm{O}(r=0.074, \mathrm{p}=0.438)$.

\section{EtOH vs. EtOH/Suc responses}

More than a half of NST taste neurons responded to 25\% EtOH. We decided to examine neuronal activities of taste cells in response to a range of concentrations of $\mathrm{EtOH}$ with/without concomitant application of sucrose. We succeeded in recording neuronal firings from 20 gustatory neurons in response to a series of EtOH concentrations: 3, 5, 10, 15, 25, and 40\% at RT. Only one $\mathrm{Qb}$ cell was non-EtOH-responsive, whereas the other 19 cells were $\mathrm{EtOH}$-responsive. The latter integrated one $\mathrm{Cb}$, one $\mathrm{Qb}$, and $17 \mathrm{Sb}$ cells. For 15 out of the $19 \mathrm{EtOH}$-responsive cells, neuronal firings in response to $\mathrm{EtOH} / \mathrm{Suc}$ were also recorded.

Fig. 3 shows a profile of NST43Q, which is a neuron of EtOHnon-responsive and $\mathrm{Qb}$ group. This cell did not respond to changes in concentration of EtOH or temperature of $\mathrm{dH}_{2} \mathrm{O}$. In contrast, one $\mathrm{Sb}$ neuron (NST95S) responded to EtOH at various concentrations. Fig. 4A and B depict a peri-stimulus time histogram of the baseline activity and evoked neuronal firing of NST95S. With or without sucrose stimulation, neuronal firing increased in a dose-dependent manner. However, neuronal responses to EtOH/ Suc have been larger, compared to $\mathrm{EtOH}$ alone.

We could not succeed in recording EtOH/Suc series-evoked responses in 4 of 19 cells. Fig. 4C demonstrates that EtOH-evoked vs. EtOH/Suc neuronal firings along the EtOH concentrations of 15 NST taste neurons at RT. We analyzed the data of these 15

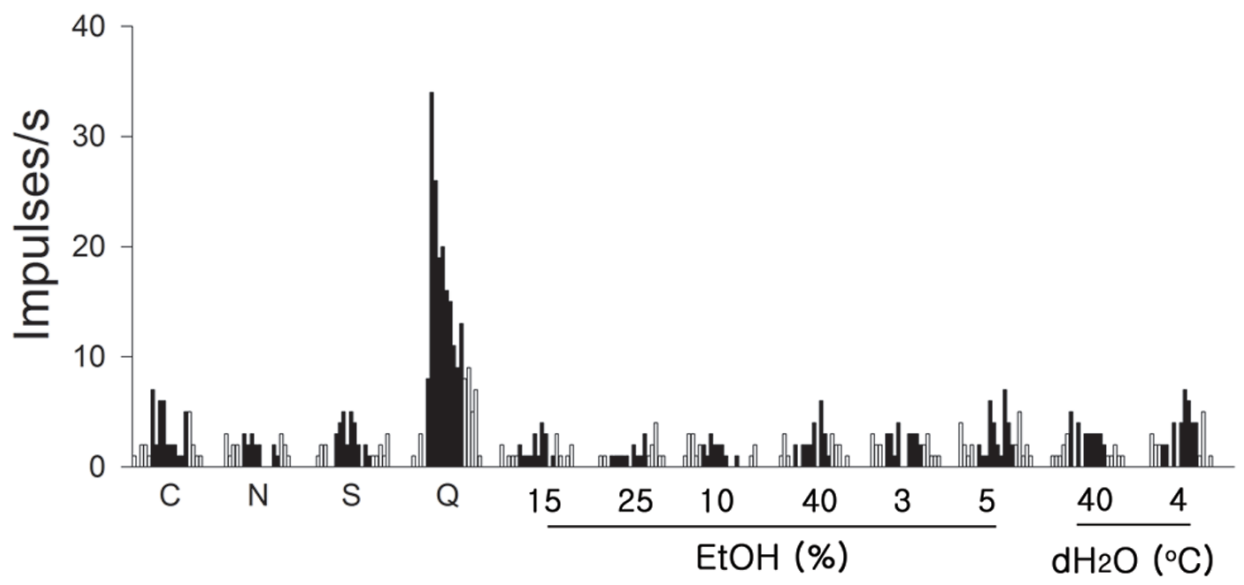

Stimuli (20 1-s bins)
Fig. 3. Response profiles for various stimuli of a typical QHCl-best neuron (NST43Q) belonging to ethanol (EtOH)-non-responsive cells. Neuronal firings for each tastant during the 10-sec stimulus are shown in filled bars, and the pre- and post-rinse periods with distilled water $\left(\mathrm{dH}_{2} \mathrm{O}\right)$ for $5 \mathrm{sec}$ are shown in open bars. The stimuli applied to the anterior tongue were sucrose $(\mathrm{S}), \mathrm{NaCl}(\mathrm{N})$, citric acid (C), QHCl (Q), 3, 5, 10, 15, 25, and $40 \%$ of EtOH, and $\mathrm{dH}_{2} \mathrm{O}$ at $40^{\circ} \mathrm{C}$ and $4^{\circ} \mathrm{C}$. This neuron only responded to $32 \mathrm{mM}$ $\mathrm{QHCl}$ as a taste stimulation. 


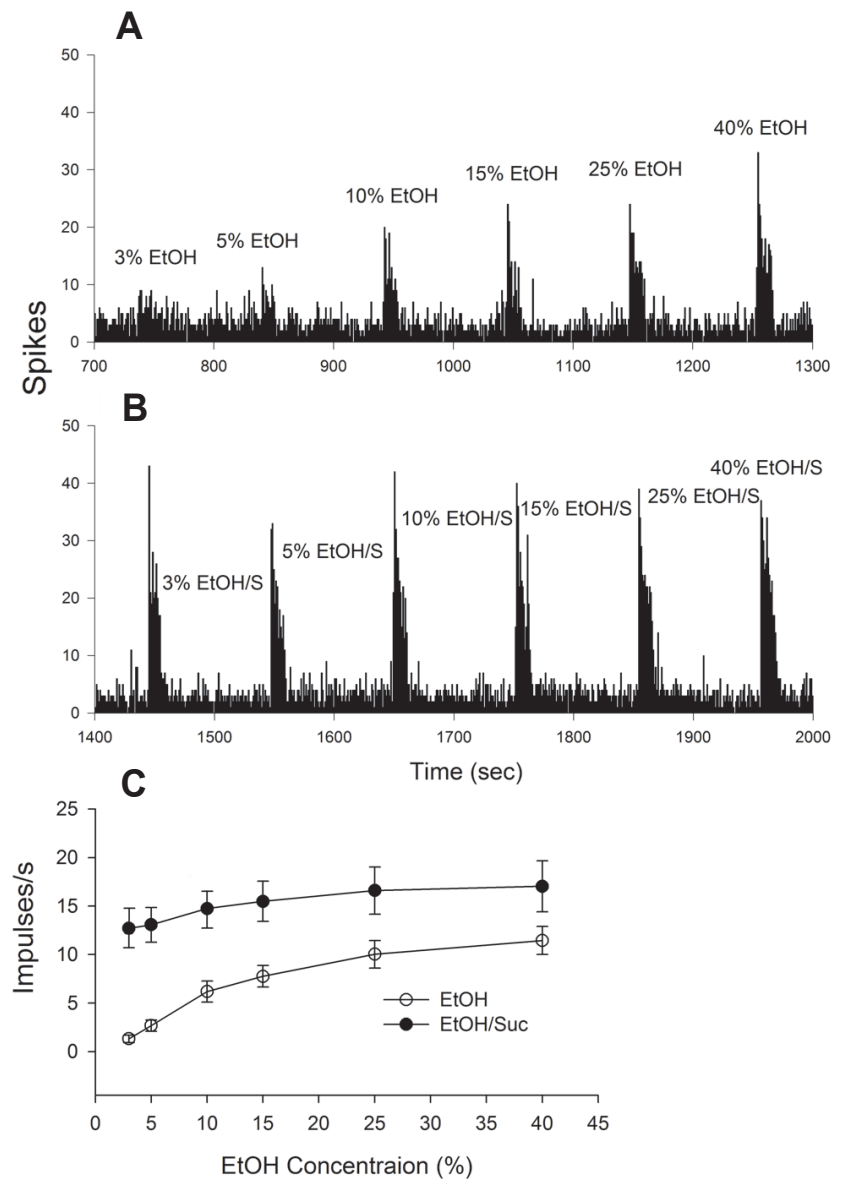

Fig. 4. A representative peri-stimulus time histogram (1-ms bins) of the impulses in a sucrose-best neuron (NST95S) in ethanol (EtOH)responsive cells. Taste stimuli are a series of $\mathrm{EtOH}(\mathrm{A})$ and a mixture of $\mathrm{EtOH}$ and $32 \mathrm{mM}$ sucrose (EtOH/Suc) (B). Evoked firings were increased in a dose-dependent manner for the stimulations with $\mathrm{EtOH}$ or $\mathrm{EtOH} /$ Suc. The stimulation with $\mathrm{EtOH} / \mathrm{Suc}$ produced larger responses than with $\mathrm{EtOH}$ alone. (C) Mean responses ( $\pm \mathrm{SE}$ ) of 15 nucleus of the solitary tract (NST) gustatory neurons to a series of 6 concentrations of EtOH (open circle) and EtOH/Suc (solid circle) stimulations at room temperature. Stimulus-evoked firings were increased in a dose-dependent manner. Responses to EtOH/Suc stimulation were greater than those to EtOH alone.

taste cells across concentrations using ANOVA. We found a significant main effect of treatment on (EtOH only and $\mathrm{EtOH} / \mathrm{Suc}$ ) $(F[1,168]=71.033, p<0.001)$ and a significant main effect of dose $(\mathrm{F}[5,168]=5.682, \mathrm{p}<0.001)$. We could not identify any significant interaction effect between these factors $(\mathrm{F}[5,168]=0.834, \mathrm{p}$ $=0.527$ ), suggesting the effect of adding sucrose on EtOH-evoked responses was independent on $\mathrm{EtOH}$ concentration.

\section{Effects of temperature}

We could test three neurons for the effect of hot $\left(40^{\circ} \mathrm{C}\right)$ and cold $\left(4^{\circ} \mathrm{C}\right)$ temperature on the responses to $\mathrm{EtOH}$ and $\mathrm{EtOH} / \mathrm{Suc}$ in a range of concentrations. Fig. 5 shows the mean responses of

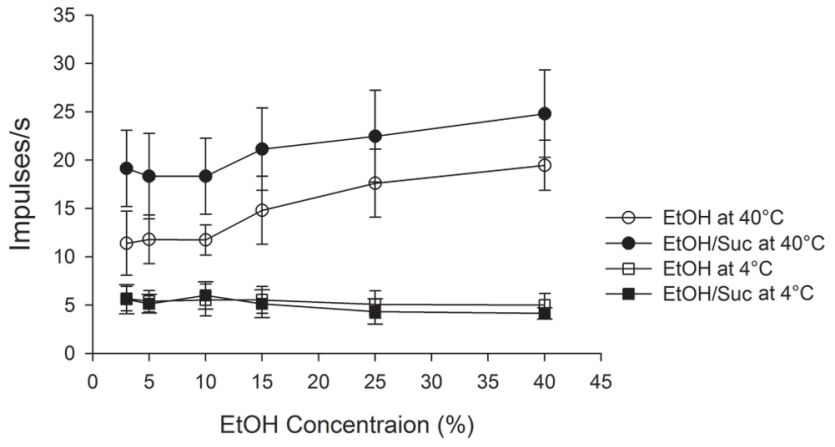

Fig. 5. Mean responses ( \pm SE) of 3 nucleus of the solitary tract (NST) gustatory neurons to a series of 6 concentrations of ethanol (EtOH) (open symbol) and EtOH/Suc (solid symbol) at $40^{\circ} \mathrm{C}$ (circle) and $4^{\circ} \mathrm{C}$ (rectangle). Neuronal responses to serial concentrations of EtOH alone or with sucrose stimulation at $40^{\circ} \mathrm{C}$ were similar to those shown at room temperature. However, this trend at $40^{\circ} \mathrm{C}$ was not shown at $4^{\circ} \mathrm{C}$.

three cells both at $40^{\circ} \mathrm{C}$ and $4^{\circ} \mathrm{C}$. We could find dose-dependent increase responses both for $\mathrm{EtOH}$ and $\mathrm{EtOH} / \mathrm{Suc}$ at $40^{\circ} \mathrm{C}$. EtOH/ Suc-evoked responses were higher than EtOH-evoked neuronal firing, despite dose. However, neuronal evoked activity in response to $\mathrm{EtOH}$ or $\mathrm{EtOH} / \mathrm{Suc}$ at $4^{\circ} \mathrm{C}$ was flat (similarly to that observed in the responses to $4^{\circ} \mathrm{C} \mathrm{dH}_{2} \mathrm{O}$ of 113 cells previously described). The mean responses to EtOH ranged between 11.4 and $19.5 \mathrm{imp} / \mathrm{s}$ at $40^{\circ} \mathrm{C}$ whereas those at RT ranged from 1.3 to 11.5 $\mathrm{imp} / \mathrm{s}$ (Fig. 4C). Similarly, EtOH/Suc responses were also higher at $40^{\circ} \mathrm{C}$ when compared to RT (18.3-24.8 vs. $\left.12.7-17.0 \mathrm{imp} / \mathrm{s}\right)$. We did not test for an effect of temperature because the number of the cells was not appropriate for statistical analysis.

\section{DISCUSSION}

In this study, we show that more than a half of medullary taste neurons respond to $25 \% \mathrm{EtOH}$ applied to the anterior tongue in hamsters. Neurons responded to EtOH in a dose-dependent way. EtOH-evoked responses correlated significantly with those observed to sucrose. Furthermore, the temperature of the stimulation solution had an effect on taste- or EtOH-evoked neuronal firing of medullary gustatory neurons.

\section{EtOH- vs. sucrose-responsiveness of NST taste neurons}

Of 113 taste-responsive neurons recorded in the hamster NST, 60 cells responded to the application of $25 \% \mathrm{EtOH}$ in the anterior tongue. In addition to $25 \% \mathrm{EtOH}$, a subset of taste neurons tested also responded in a dose-dependent way to concentrations of $\mathrm{EtOH}$ from 3 to $40 \%$. Although alcohol is not included in the basic taste modalities, some aspects of alcohol as a tastant have been investigated. Di Lorenzo et al. [32] reported that about a half of recorded NST gustatory neurons responded to $9 \% \mathrm{EtOH}$ in the 
rat. EtOH-evoked neuronal responses were also reported for the $\mathrm{CT}$ and glossopharyngeal nerves, which carry taste information from the anterior and posterior parts of the tongue in several species $[18,19,33,34]$. Lemon et al. $[20,21]$ also showed the existence of EtOH-responsive taste neurons in the rat NST. Our findings in hamsters along these previous findings in other species, strongly suggest that at least some of the stimuli-properties of $\mathrm{EtOH}$ can be encoded in the central taste pathway.

Importantly, the majority of EtOH-responsive neurons were also sucrose sensitive. A significant correlation existed between EtOH- and sucrose evoked responses, which did not exist for other taste modalities. Lemon et al. [20,21] have previously described a significant association between EtOH and sucrose responses in the rat NST. Di Lorenzo et al. [32] have also reported on at weak correlation between these two responses. In recordings from CT nerves, EtOH stimulated mainly sweet-best fibers in rats and primates $[18,19]$. Previously, positive correlation between sucrose- and $\mathrm{EtOH}$-induced neuronal firings, was also observed in pontine gustatory neurons in the hamster [22]. Oral intake of alcohol is often convoyed with a flavor of taste and olfaction [14]. However, the presence of EtOH-specific receptors has not been described in taste buds. Interestingly, gurmarin, a drug that suppresses sucrose-evoked firing in some sucrose-responsive NST cells, also inhibits EtOH-evoked responses [35]. These findings suggest that alcohol may interact with sweet-sensitive receptors at the tongue [20]. Supporting this notion, we also found that responses to $\mathrm{EtOH} / \mathrm{Suc}$ were greater than those observed to $\mathrm{EtOH}$ only, but less than the sum of the responses to those two agents in isolation.

This hypothesis also fits with the observation that the voluntary consumption of sweet solutions is positively correlated with alcohol ingestion [36,37]. Alcohol preferring subjects show a tendency for increased intake of sweets or sweet solutions both in humans and rodents [17]. Sucrose presents a palatable taste and $\mathrm{EtOH}$ is a typical rewarding substance $[13,38,39]$. Sucrose intake induces dopamine release in the nucleus accumbens (NAcc) [4042]. EtOH self-administration also increases dopamine release in the NAcc in rats [43]. Intake of alcohol and saccharin was enhanced after infusion of a mu opioid agonist into the NAcc [44]. The NAcc is a key neural structure involved in reinforcement and motivational behavior [38,41]; specifically, the NAcc shell region plays a significant role in encoding the hedonic value of orosensory stimuli and motivated behaviors [41,45]. We previously demonstrated that electrical stimulation of the NAcc shell region enhanced the spontaneous and taste-evoked neuronal firing of NST taste cells, whereas inhibiting neuronal activity of pontine gustatory neurons in the hamster $[28,46]$. Altogether, these findings suggest that the gustatory neural pathway may be involved in the appetitive aspects associated with alcohol consumption.

\section{Effects of temperature on NST taste neurons activity}

Not all gustatory neurons in the NST respond exclusively to taste stimuli. Some NST gustatory neurons also respond to mechanical or thermal stimulation in rodents [47-50]. Confirming these observations, we found that many gustatory neurons responded to $40^{\circ} \mathrm{C} \mathrm{dH_{2 }} \mathrm{O}$. Interestingly, $40^{\circ} \mathrm{C} \mathrm{dH}_{2} \mathrm{O}$-induced responses were greater in $\mathrm{EtOH}$-responsive than in $\mathrm{EtOH}$-nonresponsive neurons. Responses to $40^{\circ} \mathrm{CdH}_{2} \mathrm{O}$ correlated with those to sucrose and $25 \% \mathrm{EtOH}$. Temperature influences taste perception, especially sweetness $[24,25]$. Cruz and Green reported that warming the tongue produced perception of sweetness in humans $[23,51]$. The effects of temperature on gustatory nerves and neurons have been studied in rodents. Ogawa et al. [52] reported that sucrose sensitivity of the CT nerve was positively correlated with the responses to warming in the rat and hamster. Lundy and Contreras [53] reported that salt response of CT were smaller at $25^{\circ} \mathrm{C}$ than those at $35^{\circ} \mathrm{C}$ in rats. The influence of temperature on taste neurons in the NST has also been previously studied. Ogawa et al. [48] reported that NST taste neurons respond to thermal stimulation in the rat. In the same study, the authors also found a significant correlation between sucrose- and warming-induced neuronal responses. Warming was also described to exert an influence on sucrose-evoked responses in $\mathrm{Sb}$ neurons in mice $[54,55]$. In our study, we applied $\mathrm{RT}-\mathrm{dH}_{2} \mathrm{O}$ to the anterior tongue before and after stimulation with $\mathrm{dH}_{2} \mathrm{O}$, sucrose, $\mathrm{EtOH}$ or EtOH/ Suc at $40^{\circ} \mathrm{C}$ or $4^{\circ} \mathrm{C} \mathrm{dH}_{2} \mathrm{O}$. To ensure the temperature of the stimuli would be kept stable, the stimulation tunnels were pre-rinsed with either $40^{\circ} \mathrm{C}$ or $4^{\circ} \mathrm{C} \mathrm{dH_{2 }}$ O before delivery to the tongue.

We compared EtOH- vs. EtOH/Suc-evoked neuronal firing after stimulation at $40^{\circ} \mathrm{C}$ and $4^{\circ} \mathrm{C}$ in three gustatory neurons, respectively. Although, data could not be statistically analyzed because of the small number of observations, EtOH/Suc-evoked responses at $40^{\circ} \mathrm{C}$ were greater than those observed after $\mathrm{EtOH}$ alone. In addition, EtOH-evoked and EtOH/Suc- responses at $40^{\circ} \mathrm{C}$ were greater than those observed to the same stimulation protocol at RT. Stimulating the tongue at $4^{\circ} \mathrm{C}$ abolished the difference between $\mathrm{EtOH}$-evoked and $\mathrm{EtOH} / \mathrm{Suc}$ - responses observed at RT and $40^{\circ} \mathrm{C}$. The dose-response effects to $\mathrm{EtOH}$ were also abolished at $4^{\circ} \mathrm{C}$. We note that $4^{\circ} \mathrm{C}$ is a lower temperature than that previously used $[52,54,55]$. Breza et al. [56] found that sucrose-responsive neurons in the rat geniculate nucleus failed to respond to sucrose applied at $10^{\circ} \mathrm{C}$. Although the methods and model used are different, our data also demonstrate that warming enhance NST neural responses to sweet and EtOH.

One of the limitations of the present study was that we couldn't test effects of various temperature. Instead we focused to investigate the dose-dependent effect of $\mathrm{EtOH}$ on neuronal response of NST taste neurons in vivo. Nonetheless, we demonstrated that gustatory responses in the NST are modulated by EtOH and/or the temperature of the solution. It is well known that medullary taste neurons are under influence of many physiological aspects, 
such as sodium appetite, blood glucose level, or taste-related learning $[8,11,57]$. The stimulation of gustatory nuclei in the forebrain, including the NAcc, modulates taste responses in the NST $[27,28,58,59]$, suggesting that these descending inputs can be involved in inducing plasticity of the taste response in the NTS. Further studies are needed to examine whether $\mathrm{EtOH}$ or thermal stimulation also exert an influence on gustatory responses in more rostral taste relay nuclei, such as the $\mathrm{PbN}$ or the gustatory cortex. The investigation to examine a role of NAcc in mediating of sucrose- and EtOH-evoked neuronal activity of NST neurons will help understanding the interaction of reward and gustatory system in the central nervous system.

\section{ACKNOWLEDGEMENTS}

This study was in part supported by Gangneung-Wonju National University.

\section{CONFLICTS OF INTEREST}

The authors declare no conflicts of interest.

\section{REFERENCES}

1. Lundy RF Jr., Norgren R. Gustatory system. In: Paxinos G, editor. The rat nervous system. 3rd ed. Cambridge: Elsevier Academic Press; 2004. p.891-921.

2. Smith DV, Margolskee RF. Making sense of taste. Sci Am. 2001;284: 32-39.

3. Rolls ET. Smell, taste, texture, and temperature multimodal representations in the brain, and their relevance to the control of appetite. Nutr Rev. 2004;62(11 Pt 2):S193-S204; discussion S224-S241.

4. Rogers PJ, Hardman CA. Food reward. What it is and how to measure it. Appetite. 2015;90:1-15.

5. Rolls ET. The brain and emotion. New York: Oxford University Press; 1999.

6. Saper CB, Chou TC, Elmquist JK. The need to feed: homeostatic and hedonic control of eating. Neuron. 2002;36:199-211.

7. Giza BK, Deems RO, Vanderweele DA, Scott TR. Pancreatic glucagon suppresses gustatory responsiveness to glucose. Am J Physiol. 1993;265(6 Pt 2):R1231-R1237.

8. Giza BK, Scott TR. Blood glucose selectively affects taste-evoked activity in rat nucleus tractus solitarius. Physiol Behav. 1983;31:643650.

9. Giza BK, Scott TR. Intravenous insulin infusions in rats decrease gustatory-evoked responses to sugars. Am J Physiol. 1987;252(5 Pt 2):R994-R1002.

10. Whitehead MC. Neuronal architecture of the nucleus of the solitary tract in the hamster. J Comp Neurol. 1988;276:547-572.

11. Chang FC, Scott TR. Conditioned taste aversions modify neural responses in the rat nucleus tractus solitarius. J Neurosci. 1984;4:1850-
1862.

12. Giza BK, Ackroff K, McCaughey SA, Sclafani A, Scott TR. Preference conditioning alters taste responses in the nucleus of the solitary tract of the rat. Am J Physiol. 1997;273:R1230-R1240.

13. Brasser SM, Castro N, Feretic B. Alcohol sensory processing and its relevance for ingestion. Physiol Behav. 2015;148:65-70.

14. Bachmanov AA, Kiefer SW, Molina JC, Tordoff MG, Duffy VB, Bartoshuk LM, Mennella JA. Chemosensory factors influencing alcohol perception, preferences, and consumption. Alcohol Clin Exp Res. 2003;27:220-231.

15. Mattes RD, DiMeglio D. Ethanol perception and ingestion. Physiol Behav. 2001;72:217-229.

16. Kiefer SW, Morrow NS, Metzler CW. Alcohol aversion generalization in rats: specific disruption of taste and odor cues with gustatory neocortex or olfactory bulb ablations. Behav Neurosci. 1988;102:733739 .

17. Kampov-Polevoy AB, Garbutt JC, Janowsky DS. Association between preference for sweets and excessive alcohol intake: a review of animal and human studies. Alcohol Alcohol. 1999;34:386-395.

18. Hellekant G, Danilova V, Roberts T, Ninomiya Y. The taste of ethanol in a primate model: I. Chorda tympani nerve response in Macaca mulatta. Alcohol. 1997;14:473-484.

19. Sako N, Yamamoto T. Electrophysiological and behavioral studies on taste effectiveness of alcohols in rats. Am J Physiol. 1999; 276:R388-R396.

20. Lemon CH, Brasser SM, Smith DV. Alcohol activates a sucroseresponsive gustatory neural pathway. J Neurophysiol. 2004;92:536544.

21. Lemon CH, Wilson DM, Brasser SM. Differential neural representation of oral ethanol by central taste-sensitive neurons in ethanolpreferring and genetically heterogeneous rats. J Neurophysiol. 2011;106:3145-3156.

22. Cho YK. Relationship between alcohol and sucrose/thermal stimulation in pontine taste neurons in the hamster. Exp Neurobiol. 2007;16:79-87.

23. Cruz A, Green BG. Thermal stimulation of taste. Nature. 2000;403: 889-892.

24. Bartoshuk LM, Rennert K, Rodin J, Stevens JC. Effects of temperature on the perceived sweetness of sucrose. Physiol Behav. 1982;28: 905-910.

25. Green BG, Frankmann SP. The effect of cooling on the perception of carbohydrate and intensive sweeteners. Physiol Behav. 1988;43:515519.

26. Cho YK, Li CS, Smith DV. Gustatory projections from the nucleus of the solitary tract to the parabrachial nuclei in the hamster. Chem Senses. 2002;27:81-90.

27. Cho YK, Li CS, Smith DV. Taste responses of neurons of the hamster solitary nucleus are enhanced by lateral hypothalamic stimulation. J Neurophysiol. 2002;87:1981-1992.

28. Li CS, Lu DP, Cho YK. Descending projections from the nucleus accumbens shell excite activity of taste-responsive neurons in the nucleus of the solitary tract in the hamster. J Neurophysiol. 2015; 113:3778-3786.

29. Duncan HJ, Smith DV. Concentration-response functions for thirty chemical stimuli in the hamster solitary nucleus. Chem Senses. 1992;17:616.

30. Smith DV, Travers JB. A metric for the breadth of tuning of gusta- 
tory neurons. Chem Senses. 1979;4:215-229.

31. McPheeters M, Hettinger TP, Nuding SC, Savoy LD, Whitehead MC, Frank ME. Taste-responsive neurons and their locations in the solitary nucleus of the hamster. Neuroscience. 1990;34:745-758.

32. Di Lorenzo PM, Kiefer SW, Rice AG, Garcia J. Neural and behavioral responsivity to ethyl alcohol as a tastant. Alcohol. 1986;3:55-61.

33. Danilova V, Hellekant G. The taste of ethanol in a primate model. II. Glossopharyngeal nerve response in Macaca mulatta. Alcohol. 2000;21:259-269.

34. Hellekant G. Electrophysiological investigation of the gustatory effect of ethyl alcohol. II. A single fibre analysis in the cat. Acta Physiol Scand. 1965;64:398-406.

35. Lemon CH, Imoto T, Smith DV. Differential gurmarin suppression of sweet taste responses in rat solitary nucleus neurons. J Neurophysiol. 2003;90:911-923.

36. Kampov-Polevoy AB, Kasheffskaya OP, Sinclair JD. Initial acceptance of ethanol: gustatory factors and patterns of alcohol drinking. Alcohol. 1990;7:83-85.

37. Kampov-Polevoy AB, Overstreet DH, Rezvani AH, Janowsky DS. Saccharin-induced increase in daily fluid intake as a predictor of voluntary alcohol intake in alcohol-preferring rats. Physiol Behav. 1995;57:791-795.

38. Berridge KC. Pleasures of the brain. Brain Cogn. 2003;52:106-128.

39. Levine AS, Kotz CM, Gosnell BA. Sugars: hedonic aspects, neuroregulation, and energy balance. Am J Clin Nutr. 2003;78:834S-842S.

40. Hajnal A, Smith GP, Norgren R. Oral sucrose stimulation increases accumbens dopamine in the rat. Am J Physiol Regul Integr Comp Physiol. 2004;286:R31-R37.

41. Norgren R, Hajnal A, Mungarndee SS. Gustatory reward and the nucleus accumbens. Physiol Behav. 2006;89:531-535.

42. Smith GP. Accumbens dopamine mediates the rewarding effect of orosensory stimulation by sucrose. Appetite. 2004;43:11-13.

43. Weiss F, Lorang MT, Bloom FE, Koob GF. Oral alcohol self-administration stimulates dopamine release in the rat nucleus accumbens: genetic and motivational determinants. J Pharmacol Exp Ther. 1993;267:250-258.

44. Zhang M, Kelley AE. Intake of saccharin, salt, and ethanol solutions is increased by infusion of a mu opioid agonist into the nucleus accumbens. Psychopharmacology (Berl). 2002;159:415-423.

45. Loriaux AL, Roitman JD, Roitman MF. Nucleus accumbens shell, but not core, tracks motivational value of salt. J Neurophysiol. 2011;106:1537-1544.
46. Li CS, Chung S, Lu DP, Cho YK. Descending projections from the nucleus accumbens shell suppress activity of taste-responsive neurons in the hamster parabrachial nuclei. J Neurophysiol. 2012;108:1288-1298.

47. Hayama T, Ito S, Ogawa H. Responses of solitary tract nucleus neurons to taste and mechanical stimulations of the oral cavity in decerebrate rats. Exp Brain Res. 1985;60:235-242.

48. Ogawa H, Hayama T, Yamashita Y. Thermal sensitivity of neurons in a rostral part of the rat solitary tract nucleus. Brain Res. 1988;454: 321-331.

49. Ogawa H, Imoto T, Hayama T. Responsiveness of solitario-parabrachial relay neurons to taste and mechanical stimulation applied to the oral cavity in rats. Exp Brain Res. 1984;54:349-358.

50. Travers SP, Norgren R. Organization of orosensory responses in the nucleus of the solitary tract of rat. J Neurophysiol. 1995;73:21442162 .

51. Green BG, George P. 'Thermal taste' predicts higher responsiveness to chemical taste and flavor. Chem Senses. 2004;2:617-628.

52. Ogawa H, Sato M, Yamashita S. Multiple sensitivity of chordat typani fibres of the rat and hamster to gustatory and thermal stimuli. J Physiol. 1968;199:223-240.

53. Lundy RF Jr, Contreras RJ. Temperature and amiloride alter taste nerve responses to $\mathrm{Na}^{+}, \mathrm{K}^{+}$, and $\mathrm{NH}_{4}^{+}$salts in rats. Brain Res. 1997; 744:309-317.

54. Li J, Lemon $\mathrm{CH}$. Influence of stimulus and oral adaptation temperature on gustatory responses in central taste-sensitive neurons. $J$ Neurophysiol. 2015;113:2700-2712.

55. Wilson DM, Lemon CH. Temperature systematically modifies neural activity for sweet taste. J Neurophysiol. 2014;112:1667-1677.

56. Breza JM, Curtis KS, Contreras RJ. Temperature modulates taste responsiveness and stimulates gustatory neurons in the rat geniculate ganglion. J Neurophysiol. 2006;95:674-685.

57. Cho YK, Smith ME, Norgren R. Low-dose furosemide modulates taste responses in the nucleus of the solitary tract of the rat. Am J Physiol Regul Integr Comp Physiol. 2004;287:R706-R714.

58. Cho YK, Mao L, Li CS. Modulation of solitary taste neurons by electrical stimulation of the ventroposteromedial nucleus of the thalamus in the hamster. Brain Res. 2008;1221:67-79.

59. Li CS, Cho YK, Smith DV. Taste responses of neurons in the hamster solitary nucleus are modulated by the central nucleus of the amygdala. J Neurophysiol. 2002;88:2979-2992. 